\title{
Screening of recombinant proteins as antigens in indirect ELISA for diagnosis of bovine tuberculosis
}

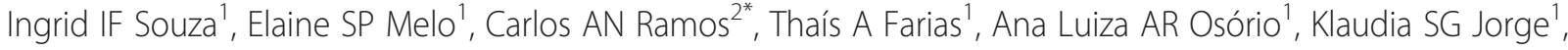
Carlos ES Vidal ${ }^{3}$, Altino S Silva ${ }^{4}$, Márcio R Silva ${ }^{5}$, Aiesca O Pellegrin ${ }^{6}$ and Flábio R Araújo ${ }^{7}$

\begin{abstract}
Bovine tuberculosis is an important infectious disease caused by Mycobacterium bovis, which is responsible for considerable economic losses. This disease constitutes a serious public health problem. Control programs in most countries, including Brazil, are based on the identification and slaughter of infected animals, as defined by the skin tuberculin test, which has its constraints. In the present study, the recombinant proteins CFP-10, ESAT-6, Mb0143, MPB83, PE5, PE13, TB10.4, TB15.3 and a chimera of ESAT-6/MPB70/MPB83 (fusion protein) were tested as ELISA antigens for the diagnosis of bovine tuberculosis. The proteins were produced in Escherichia coli, purified and tested in ELISAs with sera from 126 cattle having tested negative in the comparative intradermal tuberculin test (CITT) and 107 sera from cattle having tested positive in the CITT. Also, 236 sera from two BTB-free beef cattle herds were tested. Among the proteins tested, only the ESAT-6/MPB70/MPB83 chimera demonstrated satisfactory agreement with the CITT (kappa index: 0.688), reflecting in $83.2 \%$ sensitivity and $86.5 \%$ specificity. The ELISA absorbances of the cattle sera from BTB-free herds showed similar levels to those of CITT positive cattle, probably as the result of successive skin tuberculinizations to define the BTB-free status of the herds. However, the ELISA with the ESAT-6/MPB70/MPB83 chimera was useful to discriminate BTB positive and negative cattle in herds prior to the tuberculin skin test.
\end{abstract}

Keywords: Serology, ELISA, Recombinant proteins, Mycobacterium bovis, Cattle

\section{Background}

Bovine tuberculosis is a chronic infectious disease caused by Mycobacterium bovis, which affects cattle (Wobeser 2009), other domesticated species, wild animals and humans (Gutierrez et al. 1998; Michel et al. 2011). This disease causes economic losses in livestock farming and poses a health risk to the population that consumes products of animal origin (Lilebaum et al. 2001; Bennett and Cooke 2006).

The detection of tuberculosis in cattle is based mainly on the measurement of delayed hypersensitivity following the intradermal injection of $M$. bovis antigens, which are usually purified protein derivatives (Whelan et al. 2011). Despite the effectiveness of diagnostic approaches based on the detection of the cellular immune response to $M$. bovis antigens, skin tests must be conducted in vivo, which is difficult in large-scale epidemiological surveys and

\footnotetext{
* Correspondence: carlosanramos@yahoo.com.br

2DTI CNPq grant holder, Embrapa Gado de Corte, Campo Grande, MS, Brazil Full list of author information is available at the end of the article
}

retrospective epidemiological analyses (Menzies 1999; Liu et al. 2007). Moreover, a number of chronically infected animals may go undetected even after skin and IFN- $\gamma$ tests, which places herds at risk for the bovine-to-bovine spread of infection.

Antibody responses to $M$. bovis are positively correlated with the mycobacterial-elicited pathology and antigen burden. Thus, serological tests may increase the degree of detection of animals infected with $M$. bovis (Whelan et al. 2011). Serological tests may also constitute an alternative for screening herds for $M$. bovis infection as well as retrospectively testing sera from control programs for other diseases, such as bovine brucellosis.

A limited number of antigens have been tested in immunoassays for the diagnosis of bovine tuberculosis. Antigens such as ESAT-6, MPB70 and MPB83 have been extensively evaluated in enzyme-linked immunosorbent assay (ELISA) (Buddle et al. 1995; Amadori et al. 2002; Farias et al. 2012), however, its sensitivity and specificity 
are relatively low. Thus, the search for new antigens for serological diagnosis of bovine tuberculosis is required.

The aim of the present study was to test the recombinant proteins CFP-10, ESAT-6, Mb0143, MPB83, PE5, PE13, TB10.4, TB15.3 and a chimera of ESAT-6/MPB70/ MP83 peptides as ELISA antigens for the diagnosis of bovine tuberculosis. CFP-10, ESAT- 6 and MPB83, as a chimera of ESAT-6/MPB70/MP83 have been previously tested as an antigen (Amadori et al. 2002; Liu et al. 2007), however, Mb0143, PE5, PE13, TB10.4 and TB15.3 are being evaluated for the first time. The selection of these proteins was based on the localization of the protein in cell wall of the Mycobacerium bovis, such as PE5 and PE13 (Garnier et al. 2003; Aagaard et al. 2006), or because they are secreted proteins as TB10.4 and TB15.3 (Mattow et al. 2003). Mb0143 is a conserved hypothetical protein and has been evaluated in IFN- $\gamma$ assay (Meikle et al. 2009).

\section{Results}

\section{Production of recombinant proteins}

The fragments corresponding to the coding regions of genes cfp-10, esat-6, mb0143, mpb83, pe5, pe13, tb10.4, and $t b 15.3$ were amplified by PCR, generating amplicons of 300, 288, 459, 604, 270, 219, 231 and 408 base pairs, respectively.

Gene expressions were determined through electrophoresis in SDS-PAGE, which revealed the recombinant proteins CFP-10, chimera of ESAT-6/MPB70/MPB83, ESAT-6, MPB83, MB0143, PE5, PE13, TB10.4 and TB15.3 to have $13.6,35,12.9,20.5,28.5,17.5,12.5,11.6$ and 17.5 $\mathrm{KDa}$, respectively. These findings are consistent with the in silico predicted molecular masses analyzed using the EdiSeq of the DNASTAR program, indicating that the proteins were not post-translationally modified. In Western blotting, all recombinant proteins were recognized by the anti-6x-histidine antibody, thereby confirming gene expression.

\section{ELISAs}

Table 1 displays the optimal dilutions of sera and antigen concentrations. To evaluate the accuracy of the ELISAs, serum samples were obtained from cattle tested positive in the CITT and from cattle tested negative in the CITT from different states of Brazil. The technicians were blinded to the sample sets being tested and corresponding skin test status.

Figure 1 displays the normalized ELISA absorbances. Results are expressed as relative sensitivity or relative specificity taking CITT as the reference test. Relative sensitivity ranged from $28.0 \%$ to $83.2 \%$ and relative specificity ranged from $58.7 \%$ to $92.9 \%$. The highest relative specificity (92.9\%) of the ELISA with CFP-10 was in detriment to the relative sensitivity of the test (28.0\%).
Table 1 Optimal dilutions of sera and recombinant proteins of Mycobacterium bovis for ELISA

\begin{tabular}{lll}
\hline ELISA & \multicolumn{2}{l}{ Optimal dilutions } \\
\cline { 2 - 3 } & Serum & $\begin{array}{l}\text { Recombinant proteins } \\
\text { (final concentration } \boldsymbol{\mu g} / \mathbf{m l} \text { ) }\end{array}$ \\
\hline CFP-10 $^{*}$ Chimera & $1: 600$ & $10,000(0.1)$ \\
ESAT-6 & $1: 600$ & $1: 5000(0.2)$ \\
Mb0143 & $1: 600$ & $1: 5000(0.2)$ \\
MPB83 & $1: 600$ & $1: 10,000(0.1)$ \\
PE13 & $1: 600$ & $1: 10,000(0.1)$ \\
PE5 & $1: 600$ & $1: 500(2.0)$ \\
TB10.4 & $1: 400$ & $1: 500(2.0)$ \\
TB15.3 & $1: 400$ & $1: 2000(0.5)$ \\
* & $1: 400$ & $1: 5000(0.2)$ \\
\hline
\end{tabular}

* Chimera - fusion of MPB70, MPB83 and ESAT-6 fragments.

Regarding the kappa test, only ELISA with the chimera of the ESAT-6/MPB70/MPB83 peptides demonstrated adequate agreement with the CITT (kappa index: 0.688; confidence interval: 0.595-0.782). ELISAs with ESAT-6, MPB83 and PE5 exhibited fair agreement with the CITT (kappa index: 0.447, 0.554 and 0.404, respectively) and the other ELISAs exhibited minimal agreement with the CITT (kappa index: <0.4).

The normalized ELISA absorbances of the cattle sera from BTB-free herds showed similar levels to those of CITT positive cattle (Figure 2).

\section{Discussion}

The performance of the ELISA with the ESAT-6/MPB70/ MPB83 chimera was superior to that of ESAT-6 or MPB83 individually. It was not possible to analyze MPB70 individually as an antigen due to problems with the purification of the recombinant protein.

The kinetics of the antibody responses to different $M$. bovis antigens is variable upon infection. Anti-MPB83 antibodies can be detected relatively early, typically around four weeks post-infection (Waters et al. 2006). Anti-ESAT6 antibodies can be detected 12 weeks after experimental infection (Lyashchenko et al. 1998). In contrast, antibodies for MBP70 usually develop 18 to 22 months after experimental infection (Harboe et al. 1990; Fifis et al. 1992). Thus, chimeras containing important epitopes of major proteins of $M$. bovis are expected to be able to detect antibodies from cattle in different stages of infection, thereby increasing the diagnostic coverage. Similar results are reported in a chemiluminescent assay with multiple antigens, in which sensitivity and specificity were superior to those of individual antigens, including ESAT-6 and MPB83 (Whelan et al. 2008). The choice for the production of a chimera of antigens instead of a cocktail of individual antigens is justified by the facility of a single expression and 


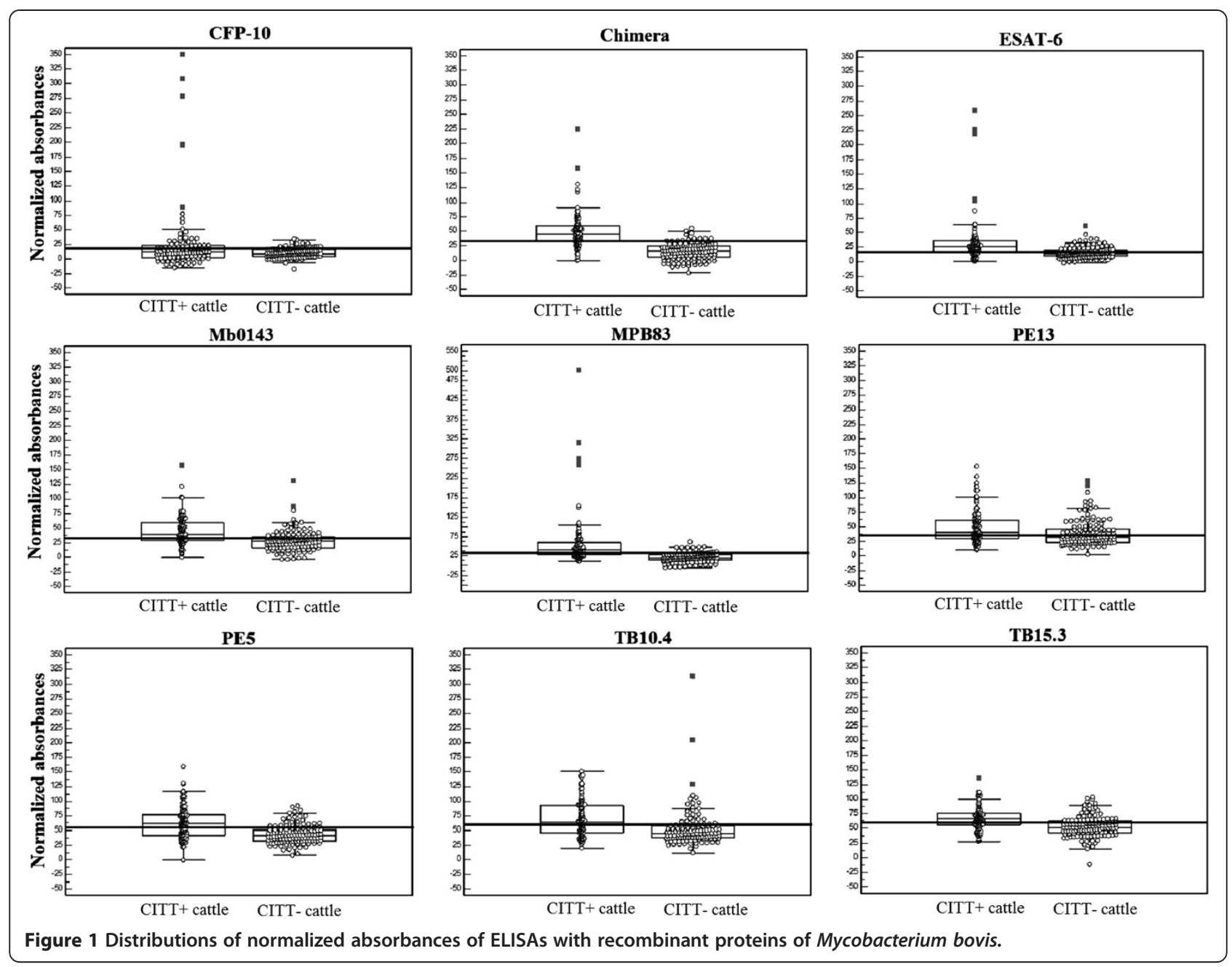

protein purification, with lower costs and no issues regarding the ratio of various antigens.

The cutoff values in this study were determined using ROC analysis, resulting, in the case of ELISA with the ESAT-6/MPB70/MPB83 chimera, in a relative sensitivity of $83.2 \%$ and an a relative specificity of $86.5 \%$, taking CITT as the reference test. If we take a practical relative specificity of $95 \%$, the relative sensitivity would be $67.3 \%$, which is similar to those found with another chimera using the same antigens (69.4\% sensitivity and $96 \%$ specificity) reported in a previous study (Liu et al. 2007). ELISA with a blend of MPB70 and MPB83 has also demonstrated good results (63\% sensitivity and 98\% specificity) (Waters et al. 2011). These findings strongly support the use of multiple antigens for the detection of cattle infected with $M$. bovis.

Besides the antigens that are traditionally used for serology (ESAT-6, MPB70 and MPB83), others that have demonstrated promising results in cellular assays were tested for serology, such as CFP-10, Mb0143, PE13, TB10.4 and TB15.3 (Aagaard et al. 2003; Aagaard et al.
2006). Among these antigens, only ELISA with PE5 demonstrated fair agreement with the CITT. Our group also found promising results with PE5 in intradermal tests with cattle experimentally immunized with the inactivated AN5 strain of $M$. bovis (data not shown). The potential of this antigen in chimera constructs will be evaluated in future studies using ELISA for M. bovis antibodies.

The similar responses of two BTB-free herds and CITT positive cattle suggest that the repeated tuberculin test, which is necessary for the establishment of the BTB-free status of the herd, may act as a booster to antibody production, as described in other studies for BTB (Harboe et al. 1990, Monaghan et al. 1994) and for bovine paratuberculosis (Varges et al. 2009). Other possibility is the sensitization of the BTB-free animals with environmental mycobacteria, and cross-reactions with the antigens, but with the herd of Embrapa Beef Cattle, which was tested with tuberculin only on the same day that serum samples were obtained, the discrimination was clearly higher. For this reason, ELISA is a useful tool 


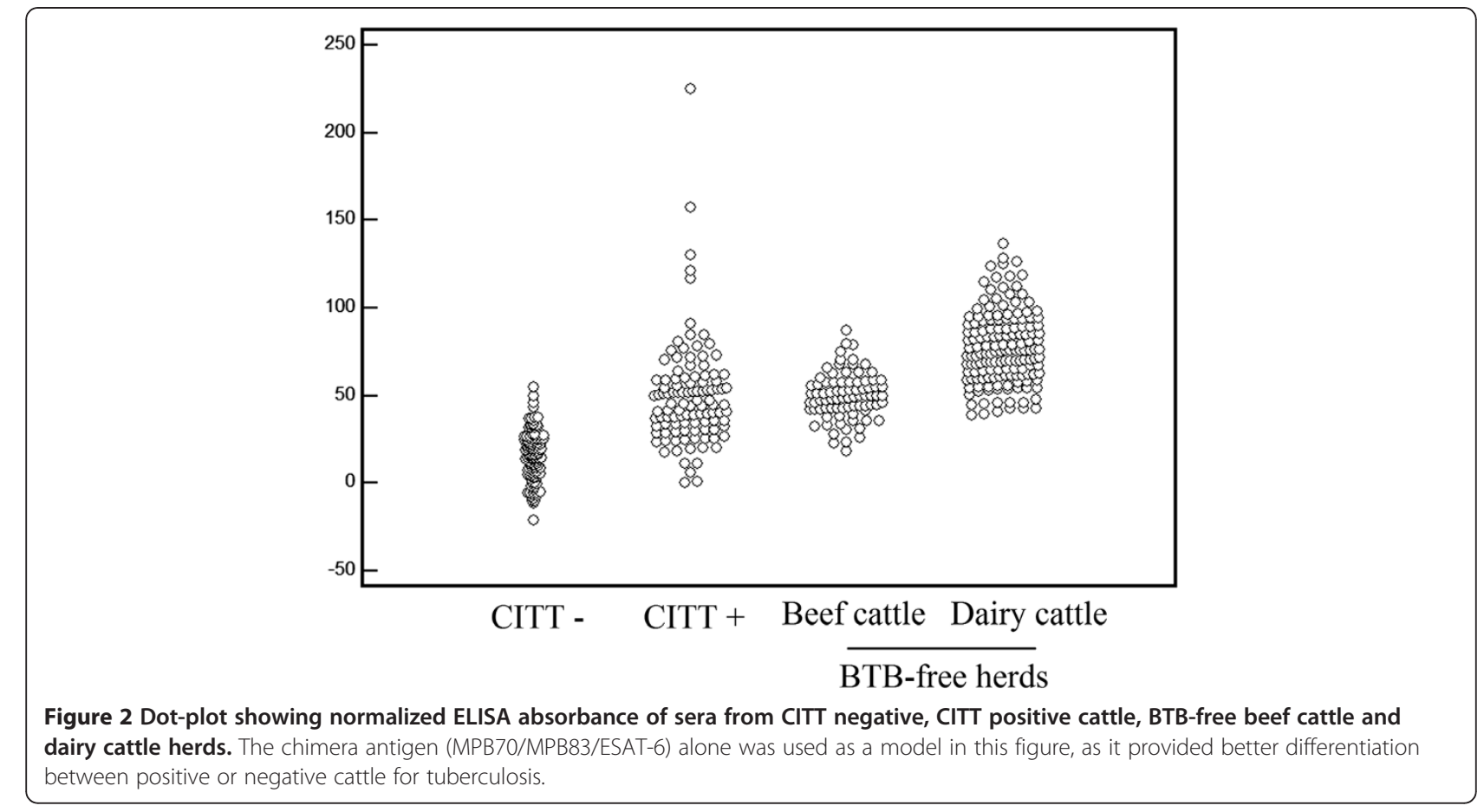

for the identification of BTB positive herds prior to the tuberculin skin test.

As in many countries, the diagnosis of bovine tuberculosis in Brazil is based on routine testing with the intradermal tuberculin test. Skin tests require containment of the animals on two occasions with a 72 -h interval for measuring the thickness of the skin fold (Brasil 2004). Management is hampered in herds raised extensively or on farms without adequate facilities, which is a common situation in developing countries. This difficulty is probably one of the main reasons for why epidemiological surveys of tuberculosis planned in the eradication program in Brazil are in a less advanced stage than those for brucellosis.

An ancillary antibody-based assay, such as ELISA with the ESAT-6/MPB70/MPB83 chimera, offers the possibility of identifying BTB positive herds using sera collected for other epidemiological studies, such as for brucellosis, prior to tuberculin skin tests, thereby increasing the diagnostic coverage. This is another useful aspect in the possible identification of cattle in advanced stages of tuberculosis with false-negative results on the skin test due to anergy (Whelan et al. 2011).

\section{Materials and methods}

\section{Antigens}

Mycobacterium bovis DNA (AN5 strain) was purified from Stonebrink's medium cultures using a commercial kit (DNeasy Blood \& Tissue kit, Qiagen). The primers were designed with the PrimerSelect program (DNAStar) to amplify the cfp-10, esat-6, mb0143, mpb83, pe5, tb10.4 and $t b 15.3$ genes (Table 2). Polymerase chain reactions (PCR) were carried out in a volume of $25 \mu \mathrm{l}$, containing $20 \mathrm{mM}$ of Tris, $\mathrm{pH} 8.4,50 \mathrm{mM}$ of $\mathrm{KCl}, 1.5 \mathrm{mM}$ of $\mathrm{MgCl}_{2}$, $250 \mu \mathrm{M}$ of each dNTP, $100 \eta \mathrm{g}$ of each primer, $0.2 \mathrm{U}$ of Taq DNA polymerase (Invitrogen) and a $50 \eta \mathrm{g}$ of $M$. bovis DNA. The amplification protocols were performed based on the characteristics of each pair of primers.

Following amplification, the genes were initially cloned in $p$ GEM-T Easy (Promega) plasmid, following the manufacturer's instructions. Cloned genes were sequenced in both directions using the BigDye Terminator v.3.1 kit (Applied Biosystems). After digestion with EcoRI, the genes were subcloned in $p E T 47-b$ (Novagen), except $t b 10.4$, which was cloned in $p E T 28-a$ (Novagen), and mpb83, which was cloned in $p R S E T-C$ (Invitrogen).

An 846-nucleotide synthetic chimera was constructed (Genone) with DNA coding sequences for the hydrophilic domains of ESAT-6, MPB70 and MPB83 and cloned in the $E c o$ RI site of $p E T 47-b$. This chimera was constructed with nucleotides 18693-19025 of mpb70 (BX248344.1, fragment 11/14), 15664-15966 of mpb83 (BX248344.1, fragment 11/ 14) and 221989-222198 of esat-6 (BX248341.1, fragment 14/14).

The Escherichia coli Rosetta strain was used as the host cells for all DNA constructs. The induction of gene expression was performed using $1 \mathrm{mM}$ of IPTG in $500 \mathrm{ml}$ of LB broth with $50 \mu \mathrm{g} / \mathrm{ml}$ of chloramphenicol and $30 \mu \mathrm{g} / \mathrm{ml}$ of kanamycin for $p E T 47-b$ and $p E T 28-a$ or $50 \mu \mathrm{g} / \mathrm{ml}$ of chloramphenicol and $100 \mu \mathrm{g} / \mathrm{ml}$ of ampicillin 


\begin{tabular}{|c|c|}
\hline Gene & DNA sequence \\
\hline \multirow[t]{2}{*}{$c f p-10$} & 5' GCAGACATGAAGACCGATGCCGCTACC 3' \\
\hline & 5' TCACAAGCCCATTTGCGAGGACAGC 3' \\
\hline \multirow[t]{2}{*}{ esat-6 } & 5' ATGACAGAGCAGCAGTGGAATTTC 3' \\
\hline & 5' CTATGCGAACATCCCAGTGAC 3' \\
\hline \multirow[t]{2}{*}{$m b 0143$} & 5' GCTTCGGAGTTCTCCCGTGCTGAA 3' \\
\hline & 5' CTCGTCGAGGGTGCCCAACTCCT 3' \\
\hline \multirow[t]{2}{*}{ mpb83 } & 5' ATGATCAACGTTCAGGCCA 3' \\
\hline & 3' GAACTCCGCCACATACCAAA 3' \\
\hline \multirow[t]{2}{*}{ pe13 } & 5' TCTTCGTGATGGCATACCC $3^{\prime}$ \\
\hline & 5' GACTTCAGTGGCCGAA 3' \\
\hline \multirow[t]{2}{*}{ pe5 } & 5' ATGACGTTGCGAGTGGTTC 3' \\
\hline & $5^{\prime}$ TCAGCCGCCCACGAC 3' \\
\hline \multirow[t]{2}{*}{ tb10.4 } & 5' ATGTACAACTACCCCGCGAT 3' \\
\hline & 5' CATGGTGTTGGCTTCATGG 3' \\
\hline \multirow[t]{2}{*}{ tb15.3 } & 5' AGCGCCTATAAGACCGTGGTGGTA 3' \\
\hline & 5' CTTGGCCCGGCGTGACACATTGG 3' \\
\hline
\end{tabular}

for $p R S E T-C$ at $37^{\circ} \mathrm{C}$ for $4 \mathrm{~h}$ at $250 \mathrm{rpm}$. Gene expression was confirmed using SDS-PAGE and Western blotting with the anti-6x-histidine monoclonal antibody (Sigma).

Recombinant proteins were solubilized with $6 \mathrm{M}$ of $\mathrm{HCl}$-guanidine and purified using the His-Trap HP agarose-nickel resin (GE Healthcare), following the manufacturer's instructions. Recombinant proteins were dialyzed with $\mathrm{PBS}$ at $4^{\circ} \mathrm{C}$ for $48 \mathrm{~h}$ and concentrations were determined by comparisons with known concentrations of bovine serum albumin in SDS-polyacrylamide gel (SDSPAGE), using the LabImage v.3.3.2 program (Loccus).

As the proteins became insoluble after dialysis, solubilization with $2 \%$ SDS was conducted as described elsewhere (Lechtzier et al. 2002).

\section{Evaluation of ELISAs}

Optimal dilutions of recombinant proteins, sera and conjugate were determined through the analysis of four sera from cattle having tested positive in the comparative intradermal tuberculin test (CITT) and four sera from cattle having tested negative in the CITT (Table 1). The CITT was carried out and interpreted according to the technical regulation of the National Program of Control and Eradication of Brucellosis and Tuberculosis of the Brazilian Ministry of Agriculture (Brasil 2004).

Sera from 107 cattle having tested positive in the CITT from Caarapó, state of Mato Grosso do Sul, Itapemirim, state of Espírito Santo and Toropi, Tapera, São Martinho da Serra and Santa Maria, state of Rio Grande do Sul, Brazil, were evaluated in the ELISAs. Sera were obtained in non-specific time-point post skin tests.
Sera from 126 cattle having tested negative in the CITT from Campo Grande, state of Mato Grosso do Sul, Brazil, were also tested in the ELISAs. The CITT negative animals were from a herd with no history of bovine tuberculosis (BTB) of Embrapa Beef Cattle. Cattle from this research center are often slaughtered in official abattoirs, and there were no reports of BTB positive animals. Blood was collected for sera on the same day that the CIIT was carried out, to avoid interference from the tuberculin test on the immune status of the animals.

Among 126 animals having tested negative in the CITT, 51 (40.5\%) were slaughtered and no lesions suggestive of BTB were found during meat inspection at an official slaughterhouse. All CITT positive animals were from herds with outbreaks of BTB, as evidenced by the presence of suggestive lesions during slaughter, the growth of acid-fast bacilli and PCR with primers for the M. tuberculosis complex (Rodriguez et al. 1995).

Moreover, 154 sera from a BTB-free beef cattle herd and 82 sera from a BTB-free dairy cattle herd were tested. The BTB-free status of the herds was established based on CITT, in compliance with the technical norms of the National Program for the Control and Eradication of Brucellosis and Tuberculosis of the Brazilian Ministry of Agriculture. Briefly, a herd is considered free of BTB after three consecutive negative tuberculin tests, with an interval of 90-120 days between the first and second tests, and an interval of 180-240 days between the second and third test (Brasil 2004).

Costar 3590 polystyrene 96-well plates (Corning) were adsorbed with each antigen in carbonate-bicarbonate buffer, $\mathrm{pH}$ 9.6, for $60 \mathrm{~min}$ at $37^{\circ} \mathrm{C}$. The plates were then blocked with $100 \mu \mathrm{l} /$ well of phosphate buffer saline with $0.1 \%$ Tween 20 (PBST) with 5\% skim milk for $60 \mathrm{~min}$ at $37^{\circ} \mathrm{C}$. After five washes with PBST, $100 \mu \mathrm{l} /$ well of the control and test sera diluted in PBST with $2 \%$ skim milk were incubated for $60 \mathrm{~min}$ at $37^{\circ} \mathrm{C}$. The plates were washed five times with PBST. Next, $100 \mu \mathrm{l}$ of monoclonal antibody anti-bovine IgG (heavy chain) horseradish peroxidase conjugate (Sigma, A5295) (dilution: 1:10,000 in PBST) were added to each well. The plates were incubated for $30 \mathrm{~min}$ at $37^{\circ} \mathrm{C}$, washed five times and $50 \mu \mathrm{l} /$ well of chromogen/substrate Fast OPD (Sigma, P9187) were added to each well. The reactions were stopped with $2.5 \mathrm{~N}$ of $\mathrm{H}_{2} \mathrm{SO}_{4}$ and the results were read on an EL-800 ELISA reader (Bio-Tek) with a $490 \mathrm{\eta m}$ filter.

To minimize the effect of intra-assay and inter-assay variations, ELISA absorbances were normalized based on the methodology described by Ramanakumar et al. (2010).

\section{Statistical analysis}

ELISA cutoff points were determined by Receiver Operating Characteristic analysis (Metz 1978; Zweig and Campbell 
1993), using the MEDCALC .10.3.0.0 software program. Agreement between CITT and ELIZA was assessed by kappa index according to Ansari-Lari (2005).

\section{Competing interests}

The authors declare that they have no competing interests.

\section{Authors' contributions}

IIFS and CESV have carried out the experiments with the ELISAs. ESPM and TAF have carried out the purification of recombinant proteins. CANR was involved with gene cloning and expression. ALARO, KSGJ, ASS, MRS and AOP carried out the tuberculin skin tests and obtained the serum samples. FRA and CANR have contributed to the experimental conception and design, to the acquisition of data, to the analysis and interpretation of data. They have also been involved in drafting and revising the manuscript. All authors read and approved the final manuscript.

\section{Purpose of the work}

We wanted to develop an ancillary diagnostic test to bovine tuberculosis, based on ELISA with recombinant proteins.

\section{Acknowledgments}

This study was funded by the Brazilian agencies CNPq (505837/2008-0) and Embrapa (0208060040000).

\section{Author details}

${ }^{1}$ Pós Graduação em Ciência Animal, Universidade Federal de Mato Grosso do Sul, Campo Grande, MS, Brazil. ${ }^{2}$ DTI CNPq grant holder, Embrapa Gado de Corte, Campo Grande, MS, Brazil. Pós Graduação em Medicina Veterinária, Universidade Federal de Santa Maria, Santa Maria, RS, Brazil. ${ }^{4}$ Instituto de Defesa Agropecuária e Florestal do Espírito Santo, Vitória, ES, Brazil. ${ }^{5}$ Embrapa Gado de Leite, Juiz de Fora, MG, Brazil. 'Embrapa Pantanal, Corumbá, MS, Brazil. ${ }^{7}$ Embrapa Gado de Corte, Campo Grande, MS 79106550, Brazil.

Received: 21 September 2012 Accepted: 17 December 2012 Published: 22 December 2012

\section{References}

Aagaard C, Govaerts M, Meikle V, Vallecillo AJ, Gutierrez-Pabello JA, SuarezGüemes F, McNair J, Cataldi A, Espitia C, Andersen P, Pollock JM (2006) Optimizing antigen cocktails for detection of Mycobacterium bovis in herds with different prevalences of bovine tuberculosis: ESAT6-CFP10 mixture shows optimal sensitivity and specificity. J Clin Microbiol 44:4326-4335

Aagaard C, Govaerts M, Meng OL, Andersen P, Pollock JM (2003) Genomic approach to identification of Mycobacterium bovis diagnostic antigens in cattle. J Clin Microbiol 8:3719-3728

Amadori M, Lyashchenko KP, Gennaro ML, Pollock JM, Zerbini I (2002) Use of recombinant proteins in antibody tests for bovine tuberculosis. Vet Microbiol 85:379-389

Ansari-Lari M (2005) Comparison between two tests results, kappa statistic instead of simple overall agreement. Vet Parasitol 133:369-370

Bennett RM, Cooke RJ (2006) Costs to farmers of a tuberculosis breakdown. Vet Rec 158:429-432

Brasil (2004) Secretaria de Defesa Agropecuária, Ministério da Agricultura, Pecuária e Abastecimento. Instrução Normativa № 6 de 8 de janeiro de 2004. Aprova o Regulamento Técnico do Programa Nacional de Controle e Erradicação da Brucelose e Tuberculose Animal. Diário Oficial da União, Brasília, pp 6-10

Buddle BM, Nolan A, McCarthy AR, Heslop J, Aldwell FE, Jackson R (1995) Evaluation of three serological assays for the diagnosis of Mycobacterium bovis infection in brushtail possums. N Z Vet J 43:91-95

Farias TA, Araújo FR, Osório SLAR, Jorge KSG, Ramos CAN, Souza IIF, Azambuja A, Soares CO, Silva MR, Pellegrin AO (2012) ELISA based on recombinant MPB70 and P27 for detection of antibodies against Mycobacterium bovis. Revista de Patologia Tropical 41:155-162

Fifis T, Costopoulos C, Corner LA, Wood PR (1992) Serological reactivity to Mycobacterium bovis protein antigens in cattle. Vet Microbiol 30:343-354

Garnier T, Eiglmeier K, Camus JC, Medina N, Mansoor H, Pryor M, Duthoy S, Lacroix C, Monsempe C, Simon S, Harris B, Atkin R, Doggett J, Mayes R, Keating L, Wheeler PR, Parkhill J, Barrell BG, Cole ST, Gordon SV, Hewinson RG
(2003) The complete genome sequence of Mycobacterium bovis. Microbiology 100:7877-7882

Gutierrez M, Tellechea J, Garcia Marin JF (1998) Evaluation of cellular and serological diagnostic tests for the detection of Mycobacterium bovis-infected goats. Vet Microbiol 62:281-290

Harboe M, Wiker HG, Duncan JR, Garcia MM, Dukes TW, Brooks BW, Turcotte C, Nagai S (1990) Protein G-based enzyme-linked mmunosorbent assay for antiMPB70 antibodies in bovine tuberculosis. J Clin Microbiol 28:913-921

Lechtzier V, Hutoran M, Levy T, Kotler M, Brenner T, Steinitz M (2002) Sodium dodecyl sulphate-treated proteins as ligands in ELISA. J Immunol Methods 270:19-26

Lilebaum W, Pessolani MCV, Fonseca LSF (2001) The use of Ag85 complex as antigen in elisa for the diagnosis of bovine tuberculosis in dairy cows in Brazil. Journal of Veterinary Medicine 48:161-166

Liu S, Guo S, Wang C, Shao M, Zhang X, Guo Y, Gong Q (2007) A novel fusion protein-based indirect enzyme-linked immunosorbent assay for the detection of bovine tuberculosis. Tuberculosis 87:212-217

Lyashchenko KP, Pollock JM, Colangeli R, Gennaro ML (1998) Diversity of antigen recognition by serum antibodies in experimental bovine tuberculosis. Infect Immun 66:5344-5449

Mattow J, Schaible UE, Schmidt F, Hagens K, Siejak F, Brestrich G, Haeselbarth G, Müller EC, Jungblut PR, Kaufmann SH (2003) Comparative proteome analysis of culture supernatant proteins from virulent Mycobacterium tuberculosis H37Rv and attenuated M. bovis BCG Copenhagen. Electrophoresis 24:3405-3420

Meikle V, Alito A, Llera AS, Gioffré A, Peralta A, Buddle BM, Cataldi A (2009) Identification of novel Mycobacterium bovis antigens by dissection of crude protein fractions. Clin Vaccine Immunol 16:1352-1359

Menzies D (1999) Interpretation of repeated tuberculin tests. Boosting, conversion, and reversion. Am J Respir Crit Care Med 159:15-21

Metz CE (1978) Basic principles of ROC analysis. Semin Nucl Med 8:283-298

Michel AL, Cooper D, Jooste J, de Klerk LM, Jolles A (2011) Approaches towards optimising the gamma interferon assay for diagnosing Mycobacterium bovis infection in African buffalo (Syncerus caffer). Prev Vet Med 98:142-151

Monaghan ML, Doherty ML, Collins JD, Kazda JF, Quinn PJ (1994) The tuberculin test. Vet Microbiol 40:111-124

Ramanakumar AV, Thomann P, Candeias JM, Ferreira S, Villa LL, Franco EL (2010) Use of the normalized absorbance ratio as an internal standardization approach to minimize measurement error in enzyme-linked immunosorbent assays for diagnosis of human papillomavirus infection. J Clin Microbiol 48:791-796

Rodriguez JG, Mejia GA, Dell PP, Patarroyo ME, Murillo LA (1995) Species-specific identification of Mycobacterium bovis by PCR. Microbiology 141:2131-2138

Varges R, Marassi CD, Oelemann W, Lilenbaum W (2009) Interference of intradermal tuberculin tests on the serodiagnosis of paratuberculosis in cattle. Res Vet Sci 86:371-372

Waters WR, Buddle BM, Vordermeier HM, Gormley E, Palmer MV, Thacker TC, Bannantine JP, Stabel JR, Linscott R, Martel E, Milian F, Foshaug W, Lawrence JC (2011) Development and evaluation of an enzyme-linked immunosorbent assay for use in the detection of bovine tuberculosis in cattle. Clin Vaccine Immunol 18:1882-1888

Waters WR, Palmer MV, Thacker TC, Bannantine JP, Vordermeier HM, Hewinson RG, Greenwald R, Esfandiari J, McNair J, Pollock JM, Andersen P, Lyashchenko KP (2006) Early antibody responses to experimental Mycobacterium bovis infection of cattle. Clin Vaccine Immunol 13:648-654

Whelan C, Shuralev E, Kwok HF, Kenny K, Duignan A, Good M, Davis WC, Clarke J (2011) Use of a multiplex enzyme-linked immunosorbent assay to detect a subpopulation of Mycobacterium bovis-infected animals deemed negative or inconclusive by the single intradermal comparative tuberculin skin test. J Vet Diagn Invest 23:499-503

Whelan C, Shuralev E, O'Keeffe G, Hyland P, Kwok HF, Snoddy P, O'Brien A, Connolly M, Quinn P, Groll M, Watterson T, Call S, Kenny K, Duignan A, Hamilton MJ, Buddle BM, Johnston JA, Davis WC, Olwill SA, Clarke J (2008) Multiplex immunoassay for serological diagnosis of Mycobacterium bovis infection in cattle. Clin Vaccine Immunol 15:1834-1838

Wobeser C (2009) Bovine tuberculosis in Canadian wildlife: An updated history. Can J Vet Res 50:1169-1176

Zweig MH, Campbell G (1993) Receiver-operating characteristic (ROC) plots: a fundamental evaluation tool in clinical medicine. Clin Chem 39:561-577

\section{doi:10.1186/2193-1801-1-77}

Cite this article as: Souza et al:: Screening of recombinant proteins as antigens in indirect ELISA for diagnosis of bovine tuberculosis. SpringerPlus 2012 1:77. 